\title{
Temporal metabolic profiling of the Quercus suber-Phytophthora cinnamomi system by middle-infrared spectroscopy
}

\author{
By P. R. Hardoim ${ }^{1,2,7}$, R. Guerra ${ }^{3}$, A. M. Rosa da Costa ${ }^{2}$, M. S. Serrano ${ }^{4}$, M. E. Sánchez ${ }^{5}$ and A. C. Coelho ${ }^{3,6}$ \\ ${ }^{1}$ CCMAR - Centre of Marine Sciences, University of Algarve, Campus Gambelas, 8005-139 Faro, Portugal; ${ }^{2}$ CIQA - Algarve Chemistry \\ Research Centre and Department of Chemistry and Pharmacy, Faculty of Sciences and Technology, University of Algarve, Campus \\ Gambelas, 8005-139 Faro, Portugal; ${ }^{3}$ CEOT - Centro de Eletrónica Optoeletronica e Telecomunicações, University of Algarve, Faro, \\ Portugal; ${ }^{4}$ Forest Pathology and Mycology Laboratory, University of California, Berkeley, CA, USA; ${ }^{5}$ Patología Agroforestal, University of \\ Córdoba, Córdoba, Spain; ${ }^{6}$ University of Algarve, Faro, Portugal; ${ }^{7}$ E-mail: phardoim@gmail.com (for correspondence)
}

\begin{abstract}
Summary
The oomycete Phytophthora cinnamomi is an aggressive plant pathogen, detrimental to many ecosystems including cork oak (Quercus suber) stands, and can inflict great losses in one of the greatest 'hotspots' for biodiversity in the world. Here, we applied Fourier transform-infrared (FT-IR) spectroscopy combined with chemometrics to disclose the metabolic patterns of cork oak roots and P. cinnamomi mycelium during the early hours of the interaction. As early as $2 \mathrm{~h}$ post-inoculation (hpi), cork oak roots showed altered metabolic patterns with significant variations for regions associated with carbohydrate, glycoconjugate and lipid groups when compared to mockinoculated plants. These variations were further extended at $8 \mathrm{hpi}$. Surprisingly, at $16 \mathrm{hpi}$, the metabolic changes in inoculated and mock-inoculated plants were similar, and at $24 \mathrm{hpi}$, the metabolic patterns of the regions mentioned above were inverted when compared to samples collected at $8 \mathrm{hpi}$. Principal component analysis of the FT-IR spectra confirmed that the metabolic patterns of inoculated cork oak roots could be readily distinguished from those of mock-inoculated plants at 2, 8 and $24 \mathrm{hpi}$, but not at 16 hpi. FT-IR spectral analysis from mycelium of $P$. cinnamomi exposed to cork oak root exudates revealed contrasting variations for regions associated with protein groups at 16 and $24 \mathrm{~h}$ post-exposure (hpe), whereas carbohydrate and glycoconjugate groups varied mainly at 24 hpe. Our results revealed early alterations in the metabolic patterns of the host plant when interacting with the biotrophic pathogen. In addition, the FTIR technique can be successfully applied to discriminate infected cork oak plants from mock-inoculated plants, although these differences were dynamic with time. To a lesser extent, the metabolic patterns of P. cinnamomi were also altered when exposed to cork oak root exudates.
\end{abstract}

\section{Introduction}

Cork oak (Quercus suber L.) is an evergreen tree, autochthonous to the Mediterranean Basin, with the largest continuous area located in the Iberian Peninsula (Bugalho et al. 2011). The cork oak savanna-like ecosystem (cork oak montado) is characterized by low-density tree stands that support one of the world's greatest 'hotspots' for biodiversity (Myers et al. 2000). Therefore, the importance of cork oak savanna far exceeds the socio-economic values derived from its main product - cork. Nevertheless, land management of the Quercus spp. 'montado' has been severely neglected in recent years (PintoCorreia and Godinho 2013; Pinto-Correia et al. 2014). Several factors are constantly challenging this human-mediated ecosystem, including numerous biotic (e.g. pathogens, insects) and abiotic (e.g. waterlogging, drought, fire and soil organic matter depletion) factors (Robin et al. 2001; Corcobado et al. 2013, 2014). Among biotic factors, root rot disease caused by the oomycete Phytophthora cinnamomi (Rands) is most likely to be responsible for the progressive decline of Iberian cork oak stands (Brasier et al. 1993; Moreira and Martins 2005; Moralejo et al. 2009; Camilo-Alves et al. 2013). Large root losses were observed on 1-year-old cork oak seedlings inoculated with P. cinnamomi, which were further aggravated by waterlogging (Robin et al. 2001). Corcobado et al. (2014) observed more severe damage on Quercus ilex caused by P. cinnamomi infection when seedlings were subjected to waterlogging followed by water deprivation.

Phytophthora cinnamomi is an aggressive soilborne pathogen that, once introduced into the ecosystem, causes significant changes in plant community structure, reducing biodiversity and threatening endemic plant species (Hardham 2005). It is believed to originate from South-East Asia (i.e. New Guinea, Malaysia), where it infects few host species (Brasier 2008). However, with its worldwide dissemination, this plant pathogen has been shown to infect over 3000 plant species, causing extensive economic losses in agriculture, horticulture and forestry alike (Hardham 2005). A wide range of physiological alterations is known to occur in plants in response to pathogen attack, including the production of reactive oxygen species (ROS), transient ion flux, cell wall strengthening, release of salicylic acid, jasmonic acid, ethylene and synthesis of pathogenesis-related proteins (Jones and Dangl 2006).

Recently, metabolomics studies have been applied to link genes to functions (Hall 2006). Metabolomics can be described as the study of all metabolites synthesized by a biological system. Among different metabolic approaches, metabolic profiling has appeared as a useful analytical tool to investigate plant-pathogen interactions (Fiehn 2002; Cameron et al. 2006). One of the metabolic profiling techniques, the Fourier transform-infrared (FT-IR) spectroscopy, has been applied successfully for differentiation of functional biochemical groups in plants challenged by abiotic perturbations and/or biotic interactions (Gidman et al. 2003; Martín et al. 2005; Martin et al. 2008; Conrad et al. 2014). However, because biological systems are composed of a myriad of polymers, macromolecules and metabolites, their infrared spectra are obviously highly 
complex, comprising the relative contributions from different functional groups, chemical structures and their interactions (Kamnev et al. 1997). Despite its complexity, FT-IR spectral analysis of control and challenged samples allows associated bands to be assigned to the main functional groups present therein. Hence, although it is not possible to identify the structure, composition and absolute concentration of individual metabolites (i.e. fingerprinting), pattern recognition can be used to interpret biological interactions and metabolic alterations (i.e. profiling; Brereton 2009).

The main objective of this study was to identify patterns of metabolic changes in samples of cork oak roots inoculated with P. cinnamomi and samples of P. cinnamomi mycelium exposed to cork oak root exudates. Specifically, we addressed the following questions: (i) How does inoculation with P. cinnamomi affect the metabolic profile of cork oak roots? (ii) How does the metabolic profile of $P$. cinnamomi vary when exposed to cork oak root exudates? (iii) What are the dynamics of the responses? FT-IR spectroscopy $\left(4000-400 \mathrm{~cm}^{-1}\right.$ ) was applied in a time series assay (i.e. 2, 8, 16, 24 h) to address these objectives.

\section{Material and methods}

\subsection{Biological material}

The patterns of metabolic profiling from two biological systems, cork oak roots and mycelium of P. cinnamomi, were investigated in a time series. For the interaction, two distinct biological assays were performed as follows: (i) the root assay, which accounted for the interaction between cork oak roots and zoospores of $P$. cinnamomi (ii) the mycelium assay, which accounted for the effect of cork oak root exudates on mycelium of $P$. cinnamomi. Mock-inoculated and mock-exposed samples were used as controls for cork oak root and mycelium of P. cinnamomi, respectively. Cork oak acorns were harvested from a single tree from Serra do Caldeirão, Algarve, Portugal, in October 2011 and stored in a dark chamber at $5^{\circ} \mathrm{C}$ until sown. To prevent root wounds, acorns were germinated on autoclaved moist paper towels and incubated in darkness at $25^{\circ} \mathrm{C}$. Germinated acorn radicles from 10-day-old cork oak seedlings with no sign of shoot apical meristem or lateral roots and ranging from 4 to $8 \mathrm{~cm}$ in length were used for the root assay.

Phytophthora cinnamomi PA-45, isolated in the Algarve region from soil associated with declining cork oak stands (Horta et al. 2008), was highly virulent on cork oak seedlings, causing extended necrotic lesions on root tissues $48 \mathrm{~h}$ after inoculation (Horta et al. 2010). To enhance the potential of infection, cultures of PA-45 were induced to produce zoospores (Chen and Zentmyer 1970). Briefly, 3-day-old cultures of P. cinnamomi PA-45 growing on V8 agar (2\% autoclaved V8 vegetable juice, Campbell Foods Belgium S.A., Puurs, Belgium, $1.6 \%$ Bacto Agar) at $24^{\circ} \mathrm{C}$ were used as inoculum for the production of young sensitive mycelium. Mycelium plugs $\left(10 \mathrm{~mm}^{2}\right)$ from the actively growing cultures were transferred to sterilized test tubes containing $20 \mathrm{ml}$ autoclaved and clarified V8 broth medium (2\%). Transferred mycelium was incubated for 1 day at $24^{\circ} \mathrm{C}$ in darkness. Sporangial production was induced by washing young and sensitive mycelial mats three times with autoclaved mineral salt solution (MSS, $10 \mathrm{~mm}$ calcium nitrate, $5 \mathrm{~mm}$ potassium nitrate and $4 \mathrm{~mm}$ magnesium sulphate) amended with filter-sterilized $(0.2 \mu \mathrm{m})$ chelated iron (Fe-EDTA, ethylenediaminetetraacetic acid ferric sodium salt; Sigma-Aldrich, Steinheim, Germany). Finally, mycelial mats were incubated in 20 ml sterile MSS amended with Fe-EDTA for 1 day at $24^{\circ} \mathrm{C}$ under fluorescent light suspended $40 \mathrm{~cm}$ above $\left(108 \mu \mathrm{mol} \mathrm{m}^{-2} \mathrm{~s}^{-1}\right.$ cool white). Zoospore release was observed under light microscopy using a Leica DM LB microscope (Wetzlar, Germany) with $100 \times$ magnification. Zoospore concentration was measured with a counting chamber (Fuchs Rosenthal; Hausser Scientific, Horsham, PA, USA) in aliquots of $100 \mu \mathrm{l}$ randomly sampled from MSS suspension $(\mathrm{n}=5)$. The final pathogen suspension for the root assay consisted of an average of $10^{5}$ zoospores in $20 \mathrm{ml}$ autoclaved MSS with sporangia-derived mycelia. For the mycelium assay, the emerged zoospores were washed once with autoclaved MSS and the sporangia-derived mycelia exposed to cork oak root exudates as described below.

\subsection{Experimental design}

The cork oak root assay consisted of seedlings inoculated with $P$. cinnamomi and mock-inoculated seedlings ('biotic' factor, $\mathrm{n}=2$ ) sampled at 2, 8, 16 and $24 \mathrm{~h}$ post-inoculation (hpi, 'temporal' factor, $\mathrm{n}=4$ ) as independent variables. Five roots were used individually for each treatment as biological replicates. Cork oak acorns with germinated radicles ranging from 4 to $8 \mathrm{~cm}$ in length were mounted on test tubes, allowing radicles, but not the acorns, to be immersed into the zoospore suspension. Roots were carefully mounted to avoid direct contact with precipitated mycelial mats; hence, host inoculation was restricted to zoospore infection. Cork oak seedlings were incubated at $24^{\circ} \mathrm{C}$ in darkness and harvested at $2,8,16$ and $24 \mathrm{hpi}$. The distal root ends were cut approximately $3 \mathrm{~cm}$ from the tips, rapidly snap-frozen in liquid nitrogen and stored at $-80^{\circ} \mathrm{C}$ until further analysis by FT-IR.

For the mycelium assay, mycelium of P. cinnamomi exposed to cork oak root exudates and autoclaved MSS (mock-exposed, 'biotic' factor, $\mathrm{n}=2$ ) was sampled at 8,16 and $24 \mathrm{~h}$ post-exposure (hpe, 'temporal' factor, $\mathrm{n}=3$ ) as independent variables. Mycelium samples at 2 hpe were also collected; however, the material was insufficient for FT-IR measurement, and thus, this time point was removed from the mycelium assay. Four mycelial mats were used individually for each treatment as biological replicates. Cork oak root exudates were collected from germinated seedlings with 6-9 true leaves and radicles ranging from 8 to $10 \mathrm{~cm}$ long $(\mathrm{n}=20)$ incubated in $900 \mathrm{ml}$ autoclaved MSS for 1 day at $24^{\circ} \mathrm{C}$ on the laboratory workbench (Lanoue et al. 2010). The hydroponic solution was filter-sterilized $(0.2 \mu \mathrm{m})$ twice to remove potential microbial contamination and plant cells. Then, the sporangia-derived mycelial mats were incubated in either 20 ml freshly filtersterilized cork oak root exudates or $20 \mathrm{ml}$ autoclaved MSS for the mock-exposed treatment at $24^{\circ} \mathrm{C}$ in darkness. At the 
predetermined sampling times (8, 16 and 24 hpe), mycelial mats were carefully detached from the cultivated agar medium with a sterile glass Pasteur pipette and gently squeezed to remove excess of MSS solution. Finally, mycelial mats were frozen in liquid nitrogen and stored at $-80^{\circ} \mathrm{C}$.

\subsection{Metabolic profiling with FT-IR spectroscopy}

Prior to FT-IR analysis, biological samples (roots and mycelium) were ground in liquid nitrogen with a mortar and pestle. To prevent transformation of metabolites and FT-IR absorbance of $\mathrm{O}-\mathrm{H}$ molecular vibration derived from water molecules, root tissues (c.a. $5 \mathrm{~g}$ ) and mycelial mats (c.a. $50 \mathrm{mg}$ ) were lyophilized for 16 and 32 h, respectively (Micro Modulyo Freeze Dryer; Edwards, Crawley, UK). Lyophilized samples were blended with KBr powder (Aldrich Chemical Co., Milwaukee, WI, USA) in a $1: 3$ ratio and vacuum-pressed (10 t) to obtain a translucent pellet. Pellets were scanned in the middle-infrared spectrum (4000-400 $\mathrm{cm}^{-1}$ ) with average over 125 scans at a resolution of four wavenumbers ( $\mathrm{cm}^{-1}$ ) in the FT-IR Spectrophotometer (TENSOR 27 series - Bruker Optik GmbH, Ettlingen, Germany). A total of four individual FT-IR spectra were generated for each biological sample: two translucent pellets were prepared for each biological sample as preparation replicates and the FT-IR spectra of these pellets were measured twice as technical replicates. The transmittance FT-IR spectra generated were preprocessed using opus software (Bruker GmbH, v 5.5). Each spectrum was corrected with straight line to compensate atmospheric $\mathrm{CO}_{2}$ peaks $\left(2400-2275 \mathrm{~cm}^{-1}\right)$, subjected to baseline correction using the rubber band algorithm with 64 points correction, smoothed with Savitzky-Golay filter (9 points) and finally vector-normalized (Lecellier et al. 2014). Briefly, first the average $y$-value of the spectrum in the region of concern was calculated. This average $y$-value was subtracted from the spectrum, resulting in a spectrum centred around $y=0$. This respective spectrum was divided by the square root of the sum of $y$-value squares. Homogeneous FT-IR spectra from technical replicates were averaged by arithmetic mean and used as representatives of the biological sample. The whole profile spectrum with 1866 reading positions (wavenumbers $\mathrm{cm}^{-1}$ ) was exported as tab-delimited file and used for recognition of patterns across treatments. In addition, the FT-IR band positions (wavenumber $\mathrm{cm}^{-1}$ ) were measured according to the centre of weight using a $0.2 \%$ sensitivity parameter from the peak-picking function (opus software) and exported as described above.

\subsection{Data and statistical analyses}

The whole FT-IR spectrum data from root and mycelium samples were kept separated, and each was imported into R project ( $R$ Core Team 2013). The FT-IR 'wavenumbers' $(n=1866)$ and transmittance values (i.e. intensity) were treated as independent and dependent variables, respectively (Wehrens 2011).

To determine significance between means of 'biotic' levels, Student's t-tests were applied to each wavenumber for each 'temporal' level. Pattern recognition was carried out with principal component analysis (PCA) by computing a singular value decomposition of the data set with function prcomp from R (Logan 2010). For this process, the original matrix was vector-normalized (along columns) by scaling the data to achieve a mean of 0 and a standard deviation of 1 (R Core Team 2013). A density plot was used to confirm normalization of the data. The ordination diagram was generated with the assigned object scores relative to each principal component (PC). For both biological systems, the two-first PCs were used to identify the levels of significance from 'biotic' and 'temporal' variables by ANova (Logan 2010).

To access metabolic patterns across 'temporal' levels, the transmittance value of assigned bands was transformed to absorbance value $\left(A=\log _{10} 1 / T\right)$. The FT-IR band matrix was vector-normalized by the min-max normalization module (Jain et al. 2005) and metabolic patterns computed by Pearson's correlation coefficient using R (R Core Team 2013) after subtracting each FT-IR absorbance band of inoculated and exposed samples from those of mock-inoculated and mockexposed in a given time, respectively. This process reduces the effect of natural metabolic evolution and provides evidence of the effect of the interaction. Pattern correlation was illustrated by a dendrogram of FT-IR bands using the function heatmap.2 from the gplots library (R Core Team 2013).

When assumptions of homogeneity of variance and normality were violated, Welch's test and the Kruskal-Wallis test, combined with Nemenyi-rank multiple comparison (1000 permutations), were applied, respectively (Logan 2010). A treatment was considered to differ significantly when an alpha level of $<0.05$ was observed.

\section{Results}

\subsection{FT-IR spectral patterns from cork oak roots inoculated with $P$. cinnamomi}

The FT-IR spectra showed typical complex patterns with many overlapping bands observed at lower $\left(1500-400 \mathrm{~cm}^{-1}\right)$ and higher frequency regions $\left(3700-2400 \mathrm{~cm}^{-1}\right.$, Fig. 1). The overall FT-IR root spectrum was characterized by a total of 18 bands (i.e. Q1-Q18) grouped according to assigned functional groups and putative biochemical groups (Table 1). Within each sampling time, FT-IR spectra from inoculated roots revealed major differences at 2, 8 and 24 hpi when compared to mock-inoculated roots (Fig. 1). At $2 \mathrm{hpi}$, inoculated plants had significantly enhanced levels of bands Q1 $\left(3481-3271 \mathrm{~cm}^{-1}\right)$ and Q15/Q16 $\left(765-711 \mathrm{~cm}^{-1}\right)$ and significantly reduced levels for bands Q2 (3122-2983 and 2952-2545 $\mathrm{cm}^{-1}$ ) and Q3 (1780-1739 $\mathrm{cm}^{-1}$ ) when compared to mock-inoculated plants (Fig. 1a). These differences were further extended (seven regions) at $8 \mathrm{hpi}$ with the intensity of bands Q1 (3489-3207 $\left.\mathrm{cm}^{-1}\right), \mathrm{Q} 12 / \mathrm{Q} 13\left(948-833 \mathrm{~cm}^{-1}\right.$ ) and region 2468-1793 (wavenumber $\mathrm{cm}^{-1}$ ) significantly enhanced in inoculated plants, whereas several bands were significantly reduced Q2 $\left(3141-2850 \mathrm{~cm}^{-1}\right)$, Q3 $\left(1766-1697 \mathrm{~cm}^{-1}\right)$, Q7 $\left(1377-1367 \mathrm{~cm}^{-1}\right)$ and region $3697-3587$ 


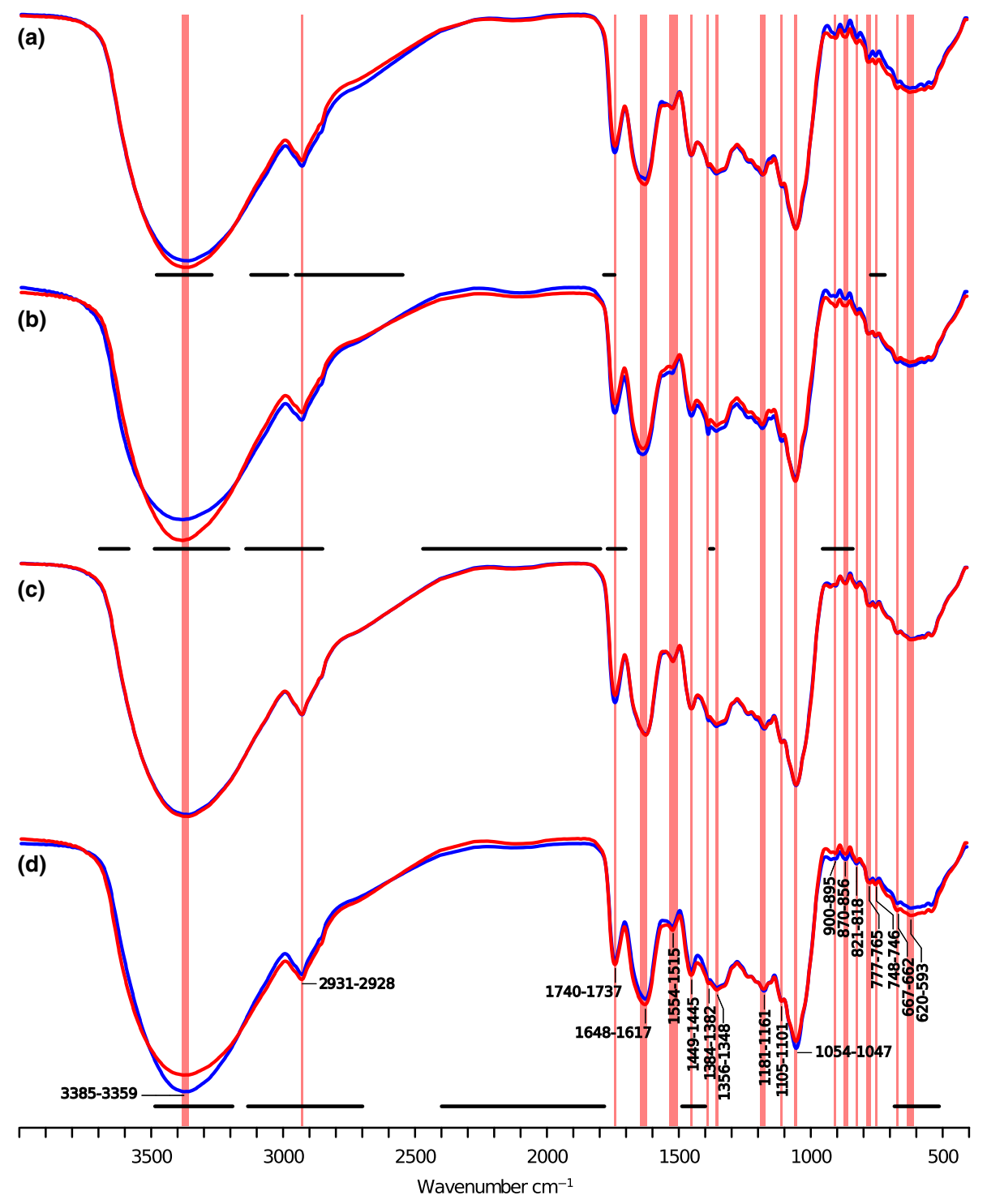

Fig. 1. Fourier transform-infrared (FT-IR) spectra of cork oak roots inoculated with P. cinnamomi (red line) and mock-inoculated (blue line). FT-IR spectra are shown as transmittance values of arithmetic means from five replicate root samples 2, 8, 16 and $24 \mathrm{~h}$ postinoculation (panels a, b, c and d, respectively). The FT-IR spectra in each panel are drawn to have identical vertical scales (i.e. same intensity for all panels). Wavenumber regions with significant levels of difference are shown in bold black lines below each set of FT-IR spectra. On panel d, the infrared wavenumbers $\left(\mathrm{cm}^{-1}\right)$ of selected bands (Q1-Q18) are also shown. FT-IR bands are shown in the range from where all cork oak samples were observed.

(wavenumber $\mathrm{cm}^{-1}$ ) when compared to mock-inoculated plants (Fig. 1b). No significant difference ( $\mathrm{p}>0.05$ ) was observed between FT-IR spectra derived from inoculated and mock-inoculated plants at 16 hpi (Fig. 1c). At 24 hpi, the intensity of band Q1 (3487-3192 $\left.\mathrm{cm}^{-1}\right)$ and region 2397-1778 $\left(\mathrm{cm}^{-1}\right)$ was significantly reduced in inoculated plants, whereas bands Q2 (3134-2698 $\left.\mathrm{cm}^{-1}\right)$, Q6 (1483-1394 $\left.\mathrm{cm}^{-1}\right)$ and Q17/Q18 $\left(675-505 \mathrm{~cm}^{-1}\right)$ were significantly enhanced when compared to mock-inoculated plants (Fig. 1d).

The contribution of each independent variable 'wavenumbers' to discriminate 'biotic' and 'temporal' factors was further explored with PCA. The ordination diagram with the object scores was generated from the two-first PCs and accounted for 75.3\% of the total variability (Fig. 2). The largest PC (PC1) mainly distinguished samples from 8 (inoculated and mockinoculated plants) and 24 hpi (mock-inoculated plants) from roots sampled at 2 and 16 hpi. These samples were scattered on the positive score gradient of PC1 and were largely characterized by the significant decrease in absorbance at the regions associated with bands Q2 (2981-2648 $\left.\mathrm{cm}^{-1}\right)$ and Q6 $\left(1461-1446 \mathrm{~cm}^{-1}\right)$. Mock-inoculated samples from $8 \mathrm{hpi}$ were significantly different $(\mathrm{p}<0.01)$ from all other sampling times, while inoculated samples from 8 hpi differed significantly from those at 2 and 16 hpi. Mock-inoculated samples from 2 and $16 \mathrm{hpi}$ were found exclusively on the negative score gradient of PC1 and were mainly characterized by absorbance at 3502-3452 (wavenumber $\mathrm{cm}^{-1}$ ). Samples from mock-inoculated plants at 8 and 24 hpi plotted, respectively, in the upper and lower score gradient of PC2 and were 


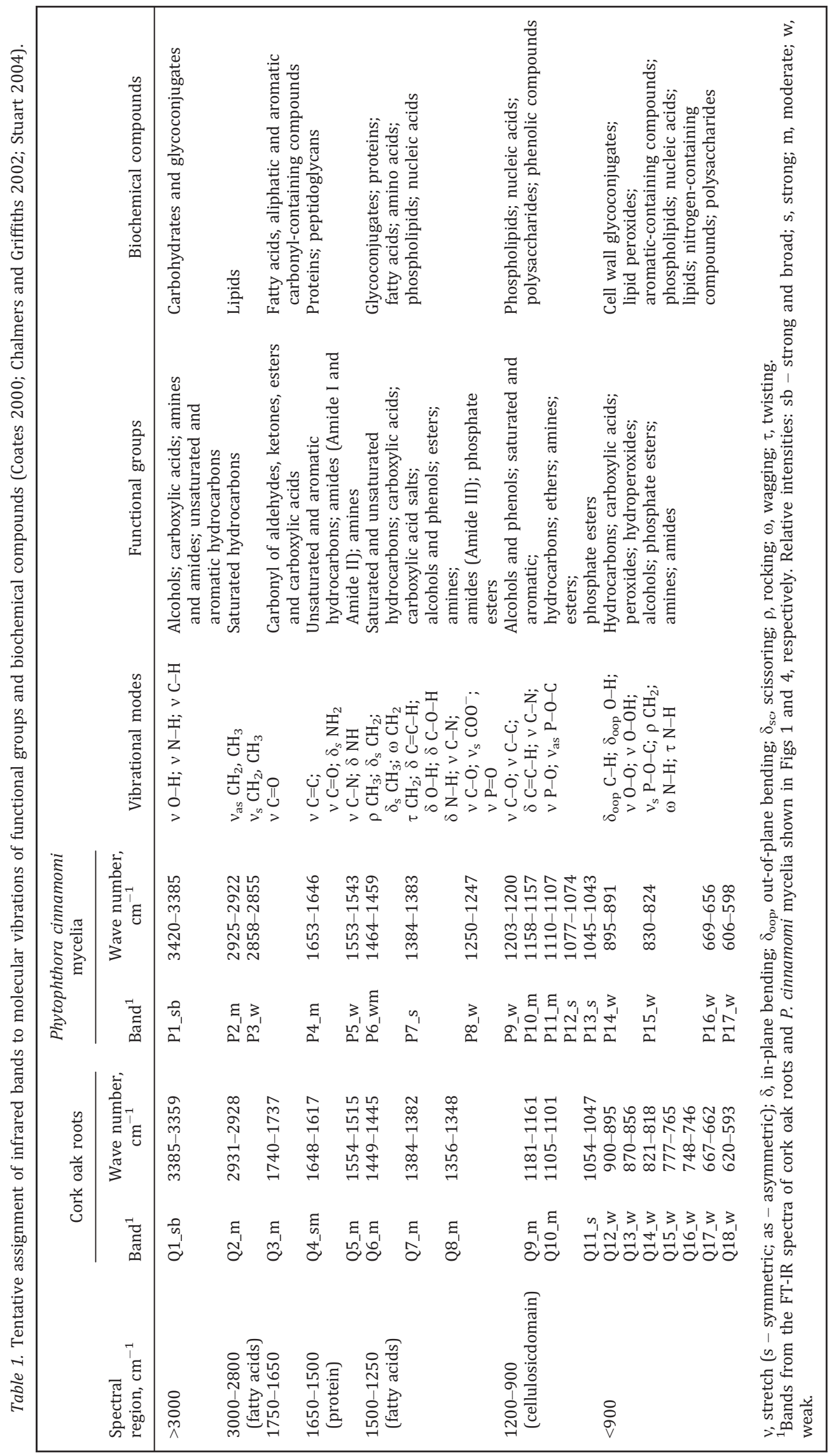




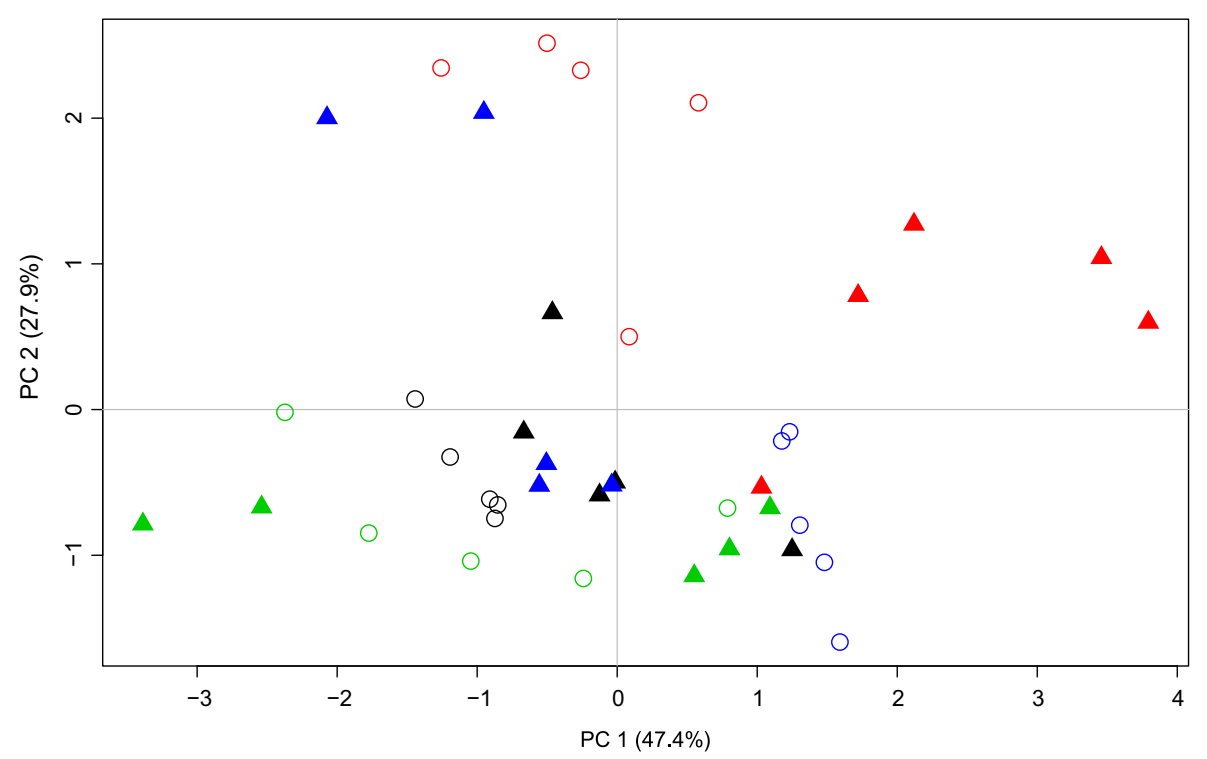

Fig. 2. Ordination diagram generated by principal component analysis (PCA) on the basis of Fourier transform-infrared (FT-IR) spectra collected from inoculated (triangle) and mock-inoculated (circle) cork oak roots. Samples collected at 2, 8, 16 and $24 \mathrm{~h}$ post-inoculation are shown in black, red, green and blue signs, respectively. The percentages indicate the proportions of variation explained by the first and second ordination axes.

significantly different $(\mathrm{p}<0.001)$ when compared to inoculated samples (Fig. 2). Four replicates from mock-inoculated samples at $8 \mathrm{~h}$ were mainly distinguished by the FT-IR spectrum at 2403-2281 (wavenumber $\mathrm{cm}^{-1}$ ), whereas mock-inoculated samples at $24 \mathrm{hpi}$ were mainly characterized by reduced absorbance at 3654-3608 $\left(\mathrm{cm}^{-1}\right)$ and associated with the band Q18 (646-507 $\left.\mathrm{cm}^{-1}\right)$.

Pattern correlation analysis revealed three conspicuous clusters of FT-IR patterns from Q. suber assigned bands that were significantly correlated $(r>0.53$; p $<0.001)$ (Figure S1). FT-IR bands Q1, Q11, Q12 and Q13 were positively correlated $(r>0.7 ; \mathrm{p}<0.001)$ and showed a reduction in the pattern of absorbance from 8 to 24 hpi (Fig. 3; Table S1). FT-IR

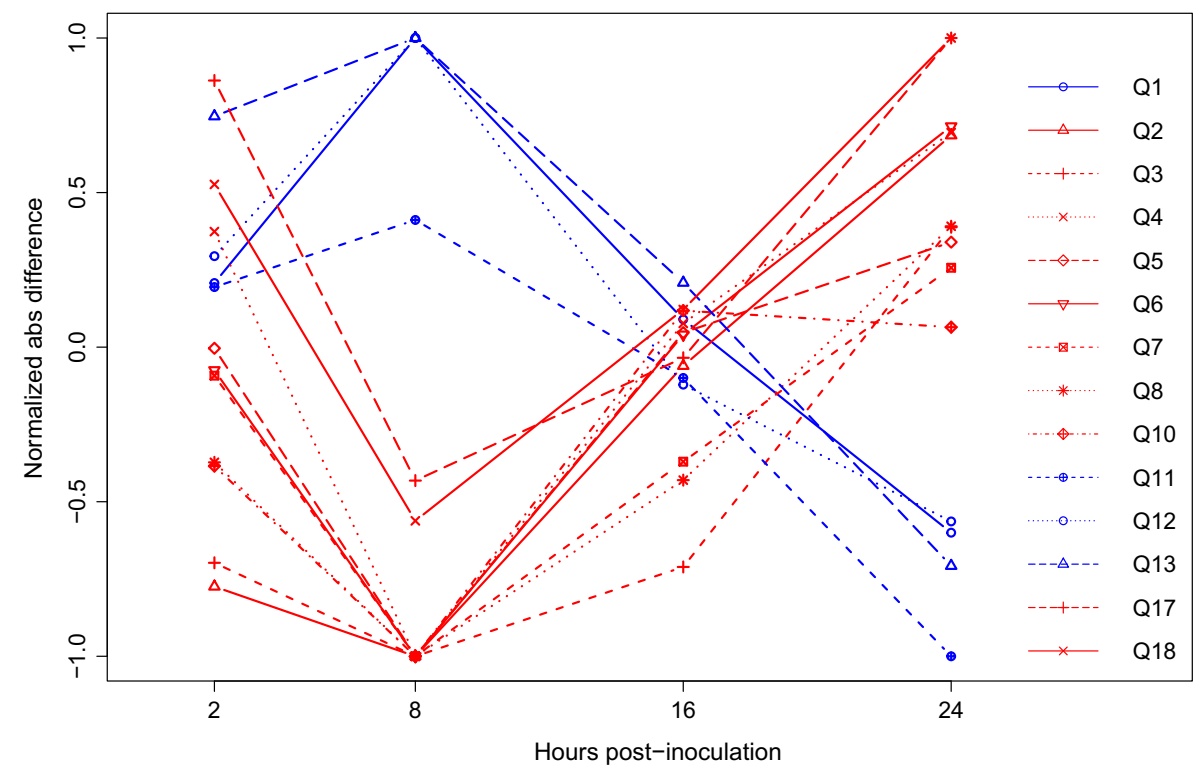

Fig. 3. Patterns of metabolic changes from Quercus suber Fourier transform-infrared (FT-IR) bands with time. Two distinct metabolic patterns of Q. suber seedlings when challenged by Phytophthora cinnamomi are shown. Metabolites related to carbohydrate groups are represented by blue (bands Q1, Q11, Q12 and Q13) lines, and those related to lipid and protein groups are represented by red (bands Q2Q10, Q17 and Q18) lines. A positive value on the $y$-axis indicates higher concentrations of metabolic groups (FT-IR bands) in the seedlings of $Q$. suber inoculated with P. cinnamomi, whereas negative values indicate higher concentrations of metabolic groups in the seedlings of Q. suber that were mock-inoculated. 
bands Q2, Q3, Q4, Q5, Q6, Q7, Q8, Q10, Q17 and Q18 were also positively correlated ( $r>0.53$; p $<0.001)$, displaying a second distinct configuration with a reduction in the pattern of absorbance at 8 hpi followed by an increase in succeeding hours (Fig. 3). Independent of the FT-IR pattern group, these bands revealed a conspicuous convergence in the pattern of absorbance at 16 hpi between inoculated and mock-inoculated plants, followed by the inverse pattern at 24 hpi when compared to samples collected at $8 \mathrm{hpi}$ (Fig. 3). The pattern of the remaining FT-IR bands Q9, Q15 and Q16 was also positive correlated $(r>0.76 ; \mathrm{p}<0.001$; Table S1).

\subsection{FT-IR spectral patterns of $P$. cinnamomi mycelium exposed to cork oak root exudates}

Mycelium of P. cinnamomi collected at 8, 16 and 24 hpe to cork oak root exudates or MSS (control treatment) displayed complex metabolic profiles with many overlapping bands at the lower frequency of the FT-IR spectrum $\left(1500-400 \mathrm{~cm}^{-1}\right.$, Fig. 4). FT-IR spectra from mycelial samples were characterized by 17 bands (P1-P17, Table 1), grouped according to assigned functional groups and putative biochemical groups (Table 1). All FT-IR spectra of P. cinnamomi mycelium had an almost undetectable weak shoulder band of carbonyl $\left(\sim 1740 \mathrm{~cm}^{-1}\right)$. Within each sampling time, specific regions of the FT-IR spectra from mycelium exposed to cork oak root exudates differed significantly when compared to spectra from mock-exposed mycelium (Fig. 4). At 8 hpe, the intensity of band P7 (1404-1348 $\mathrm{cm}^{-1}$ ) and region 3328-3240 (wavenumber $\mathrm{cm}^{-1}$ ) was significantly reduced and enhanced in mycelium samples exposed to root exudates when compared to mock-exposed mycelium, respectively (Fig. 4a). At 16 hpe, the intensity of bands P2, P3 (2974-2842 $\mathrm{cm}^{-1}$ ), P4 (1760$\left.1652 \mathrm{~cm}^{-1}\right)$, P5 (1571-1508 $\left.\mathrm{cm}^{-1}\right)$, P8/P9 (1303-1195 $\left.\mathrm{cm}^{-1}\right)$ and region 1018-968 $\left(\mathrm{cm}^{-1}\right)$ was significantly reduced in mycelium samples exposed to root exudates (Fig. 4b). At 24 hpe, the intensity of bands P1 (3492-3317 $\mathrm{cm}^{-1}$ ), P14/P15 $\left(956-788 \mathrm{~cm}^{-1}\right)$ and region 2594-1755 $\left(\mathrm{cm}^{-1}\right)$ was significantly reduced in mycelium samples exposed to cork oak root

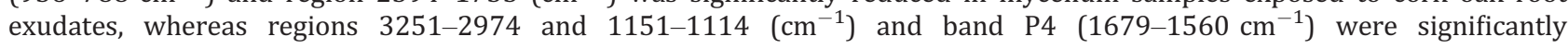
enhanced when compared to mock-exposed mycelium (Fig. 4c).

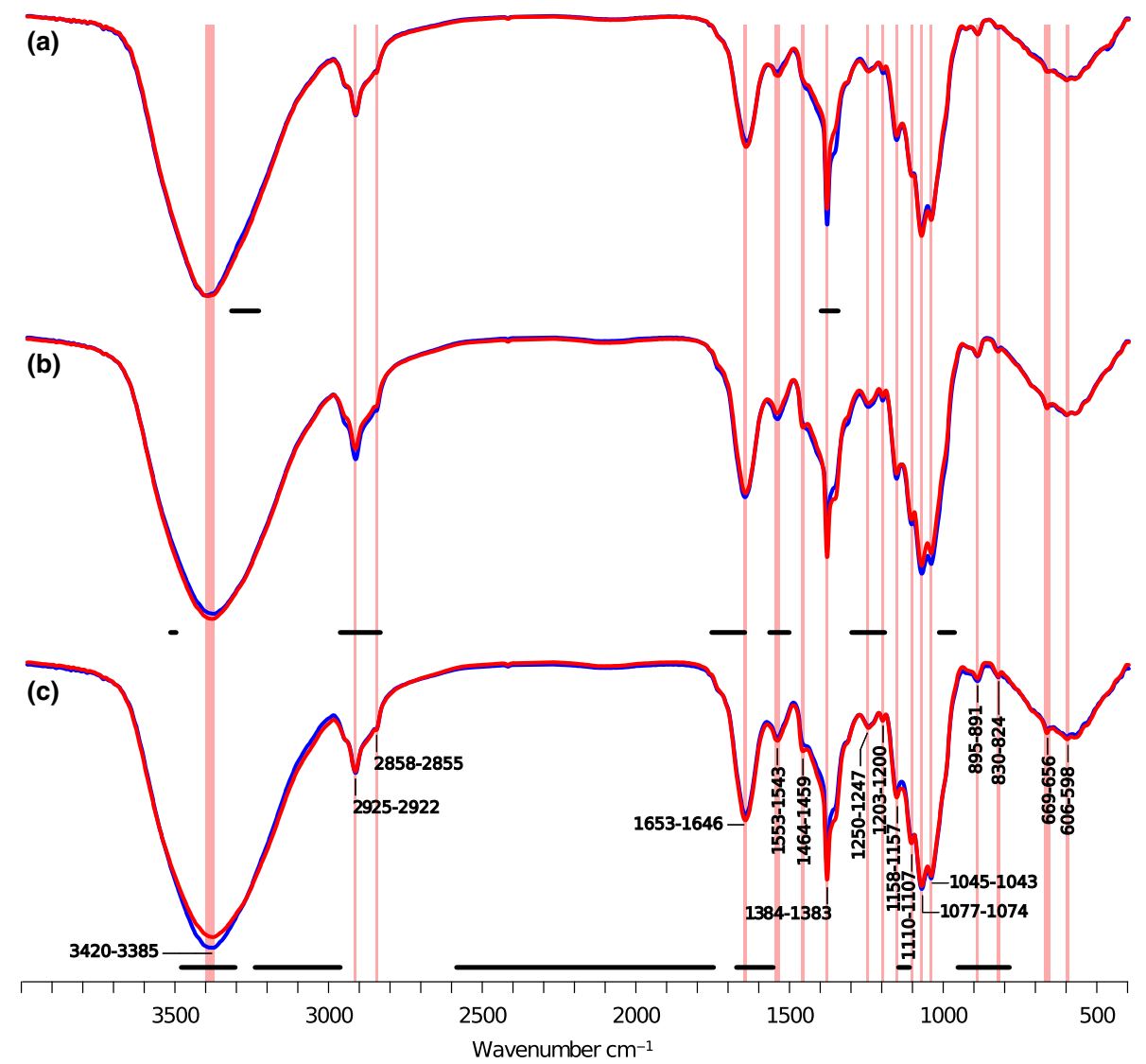

Fig. 4. Fourier transform-infrared (FT-IR) spectra of mycelium from P. cinnamomi exposed to cork oak root exudates (red line) or control (blue line). FT-IR spectra are shown as transmittance values of the arithmetic mean from four mycelial replicates 8 (panel a), 16 (b) and $24 \mathrm{~h}$ post-exposure (c). FT-IR spectra in each panel are prepared with identical vertical scales (i.e. same intensity for all panels). Wavenumber regions with significant differences are shown in bold black lines below each set of FT-IR spectra. Panel (c) also shows the infrared wavenumbers $\left(\mathrm{cm}^{-1}\right)$ of selected bands (P1-P17). FT-IR bands are shown in the range from where all mycelium samples were observed. 


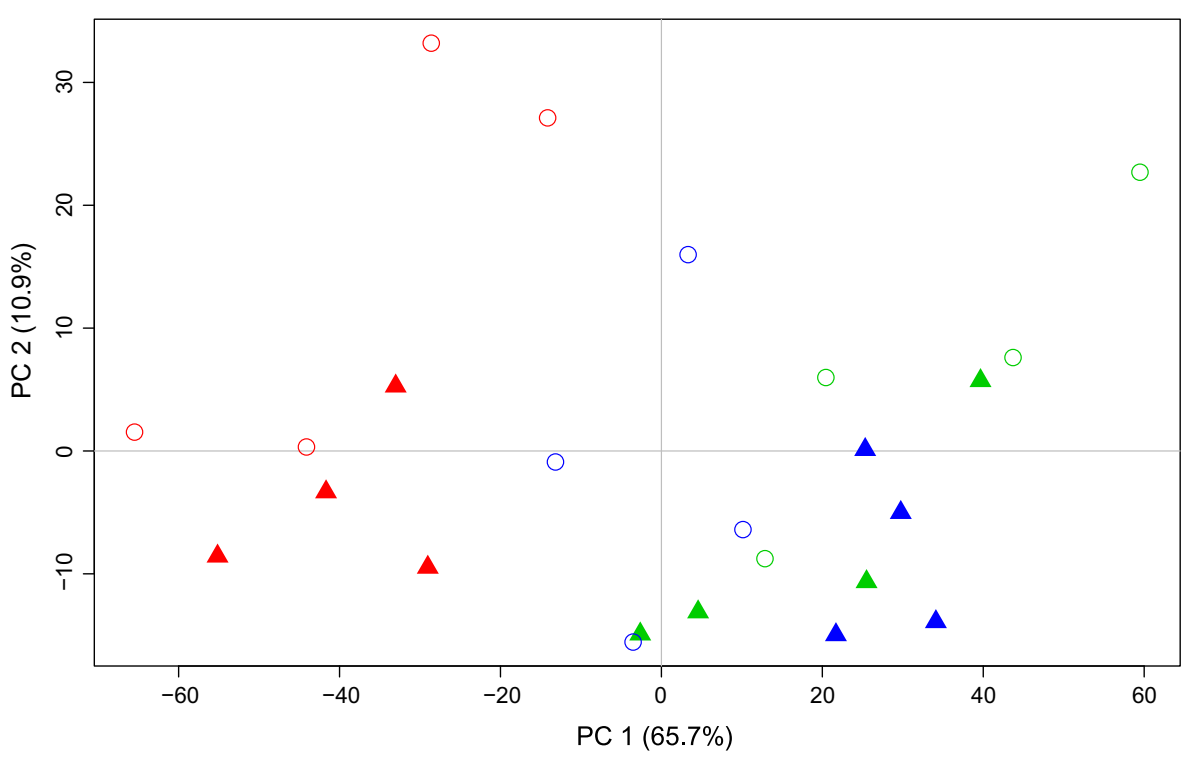

Fig. 5. Ordination diagram generated by principal component analysis (PCA) on the basis of Fourier transform-infrared (FT-IR) spectra collected from mycelium exposed to cork oak root exudates (triangle) and mock-exposed (circle). Samples collected at 8, 16 and $24 \mathrm{~h}$ post-inoculation are shown in red, green and blue signs, respectively. The percentages indicate the proportions of variation explained by the first and second ordination axes.

The ordination diagram of mycelium samples was generated from the PC1 and PC2 PCs and accounted for $76.6 \%$ of the total data variability (Fig. 5). The large variability of the score plot was explained by PC1 (65.7\%), which distinguished scores mainly by 'temporal' factor. Samples from $8 \mathrm{~h}$ were exclusively plotted on the negative score gradient of PC1 and were significantly different $(\mathrm{p}<0.01)$ from those of 16 and 24 hpe found on the central and positive score gradient of PC1. Mycelium samples from $8 \mathrm{~h}$ were mainly characterized by reduced absorbance at regions of bands P2 (3171$\left.2976 \mathrm{~cm}^{-1}\right)$, P4 $\left(1709-1655 \mathrm{~cm}^{-1}\right)$ and P5 $\left(1582-1558 \mathrm{~cm}^{-1}\right)$, while samples from 16 and 24 hpe were largely characterized by reduced absorbance at regions associated with bands P1 $\left(3489-3352 \mathrm{~cm}^{-1}\right)$, P14 $\left(872-841 \mathrm{~cm}^{-1}\right)$ and region 2596-1794 $\left(\mathrm{cm}^{-1}\right)$. At $24 \mathrm{~h}$, all samples from mycelium exposed to root exudates were closer, but distinct from samples of control mycelium, mostly scattered on the left-hand side of the plot (Fig. 5). Although PC2 showed reduced variability (only $10.9 \%$ ), samples from mycelium exposed to root exudates at 8 and 16 hpe mainly plotted at the negative score gradient of PC2 and were characterized by reduced absorbance of band P9 (1204-1196 $\mathrm{cm}^{-1}$ ) and region 980-974 (wavenumbers $\mathrm{cm}^{-1}$ ), while mycelium samples exposed to MSS were mainly scattered on the positive score gradient of PC2 and were characterized by enhanced absorbance at regions 3310-3283 and 2775-2770 (cm ${ }^{-1}$; Fig. 5).

Correlation analysis revealed six conspicuous patterns that significantly correlated within clusters of $P$. cinnamomi FT-IR assigned bands $(r>0.93$; p $<0.001$ ) (Figure S2). FT-IR bands P2, P6, P9 and P16 were positively correlated $(r>0.98$; $\mathrm{p}<0.001$ ) and showed a constant increase in the pattern of absorbance with sampling time (Fig. 6; Table S2). FT-IR bands P3, P4, P5, P8 and P11 were positively correlated $(r>0.93 ; \mathrm{p}<0.001)$ and showed distinct reductions in pattern of absorbance at 8 hpe followed by an increase at 24 hpe (Fig. 6). The four remaining patterns were observed as pairs of FT-IR bands P1/P14, P7/P15, P10/P17 and P12/P13, each of which was also positively correlated $(r>0.95 ; \mathrm{p}<0.001)$ and showed a distinct pattern of absorbance (Fig. 6).

\section{Discussion}

In contrast to other metabolic profiling techniques, for example GC-MS and LC-MS, which involve separation of molecules by chromatography, FT-IR spectroscopy detects antisymmetric vibration of polar molecules and thus generates a 'holistic' overview of major functional groups retrieved from the biological system under investigation. Hence, the rapid screening capacity and ability to detect unforeseen metabolic alterations in biological systems makes FT-IR spectroscopy a suitable technique to be used prior to any targeted metabolite analysis (Chalmers and Griffiths 2002). Nevertheless, the use of FTIR spectroscopy in woody plant-pathogen interactions is scarce and even more singular when the considering temporal effects (Martín et al. 2005; Allwood et al. 2006; Cameron et al. 2006; Martin et al. 2007, 2008; Conrad et al. 2014; Vivas et al. 2014). So, to our knowledge, this article is the first to describe temporal changes in the metabolic patterns of early interaction between cork oak roots and P. cinnamomi by FT-IR spectroscopy.

At a first glance, the hyperspectral data generated by the FT-IR technique revealed high complexity. Therefore, we relied on statistical analyses to discriminate FT-IR regions for each investigated variable (i.e. 'biotic' and 'temporal') and to correlate changes in metabolic patterns from assigned bands along the 'temporal' variable. It is clear, even at the earlier 


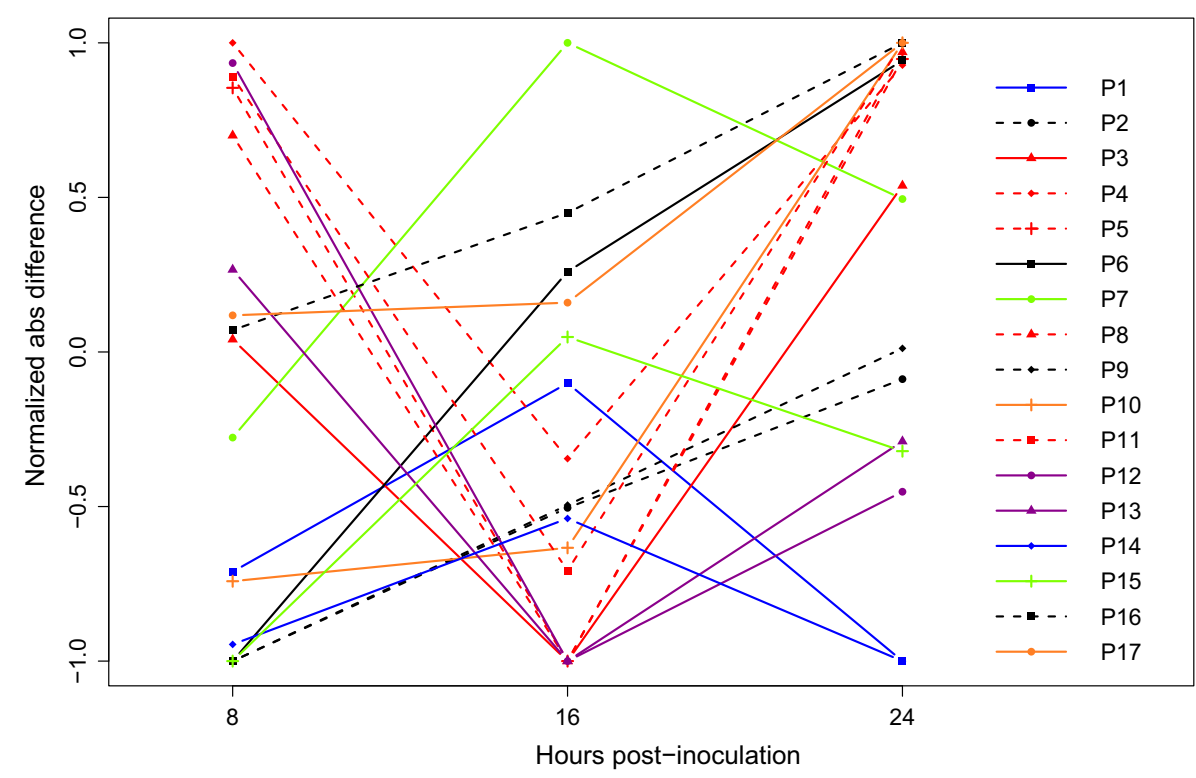

Fig. 6. Patterns of metabolic changes in Phytophthora cinnamomi Fourier transform-infrared (FT-IR) bands with time. Six distinct metabolic patterns of $P$. cinnamomi mycelium when exposed to Quercus suber root exudates are shown. Positive values on the $y$-axis indicate higher concentrations of metabolic groups (FT-IR bands) in the mycelium of P. cinnamomi exposed to Q. suber root exudates, whereas negative values indicate higher concentrations of metabolic groups in the mycelium of $P$. cinnamomi that was mock-exposed.

sampling time, that cork oak plants showed abrupt alterations to the metabolites when inoculated with P. cinnamomi, suggesting rapid adjustments in the host metabolic profile. Also, the contribution of P. cinnamomi metabolites to the overall metabolic pattern observed with time cannot be excluded. Colonization of susceptible hosts by Phytophthora spp. results in a significant increase in pathogen biomass within days of inoculation (Kamoun et al. 1998; Asai et al. 2010).

In this work, the FT-IR analysis of $Q$. suber plants inoculated with P. cinnamomi revealed two very distinct patterns that contrasted in terms of concentration of functional groups with time. Carbohydrate (band Q1) and cell wall glycoconjugate (bands Q11, Q12 and Q13) groups were enhanced, as early as $2 \mathrm{~h}$ after inoculation, until $8 \mathrm{hpi}$, whereas lipid (bands Q2, Q6, Q7 and Q8), carbonyl (band Q3), protein (bands Q4 and Q5) and cell wall glycoconjugate (bands Q10, Q17 and Q18) groups were drastically reduced at the same time. Photoassimilates are synthesized to supply essential energy for cell growth and development. Upon invasion, P. cinnamomi probably disrupted this state of homeostasis. However, it was not clear whether the increment in the host carbohydrates was due to the pathogen reprogramming host metabolism to support pathogenesis (Hückelhoven 2007; Martin and Kamoun 2012) or was a restructuring of host metabolism to counter pathogen invasion. For instance, cell wall-associated defence responses might include papillae apposition. Addition of glycoconjugate groups at region of bands Q11 and Q12 ( \pm 1050 and $\pm 900 \mathrm{~cm}^{-1}$, respectively) has been associated with the apposition of xyloglucans (Morris et al. 2003). Xyloglucan, a hemicellulosic polysaccharide important in the formation of primary wood cell walls, is also one of the constituents of papillae during cell wall apposition upon oomycete invasion (Enkerli et al. 1997; Underwood 2012; Oßwald et al. 2014).

The reduction in the level of lipid groups was also detected in plants of Brachypodium distachyon when inoculated with the fungus Magnaporthe grisea (Allwood et al. 2006). A central event in plant resistance during progress of pathogen invasion is the activation of ROS generation, a reaction also known as the 'oxidative burst' (De Jong et al. 2004; Testerink and Munnik 2005). Increases in ROS lead to the oxidative degradation of lignin, cellulose and lipid groups, thus affecting membrane permeability and consequently inducing apoptosis (Spiteller 2003; Torres et al. 2006). Although the concentration of ROS was not directly quantified in this work, cork oak plants inoculated with P. cinnamomi had extensive root necrosis, an indirect sign of the 'oxidative burst' (Horta et al. 2010; Medeira et al. 2012).

After the initial host disturbance, no differences between the FT-IR spectra from inoculated and mock-inoculated plants at 16 hpi were found. This result might be explained by the reorganization of the host cell metabolites observed after being subjected to biotic (Vega-Sanchez et al. 2005; Kelley et al. 2010) and abiotic stresses (Kim et al. 2007). A new metabolic pattern emerged at $24 \mathrm{hpi}$ with the accumulation of lipid, protein and aromatic-containing groups, and a reduction in the level of carbohydrate and glycoconjugate groups. In elm trees (Ulmus minor), the reduction in carbohydrate groups was inversely correlated to the increasing lignification in the xylem several days after inoculation with Ophiostoma novo-ulmi, suggesting activation of induced host defence responses (Martín et al. 2005). The increase in the phospholipid phosphatidic acid (PA), observed in FT-IR region 1350-1250 $\mathrm{cm}^{-1}$ (band Q8), has been associated with resistance of $B$. distachyon when challenged by the fungus M. grisea (Allwood et al. 2006). PA is a signalling molecule involved in various cell processes, including defence against biotic challenges, that leads to the oxidative burst in plants (De Jong et al. 2004; Allwood et al. 2006; Wang et al. 2006). ROS will also activate the pentose phosphate pathway, providing pentose intermediates for the 
production of aromatic compounds, such as phenolic compounds and their derivatives that might contribute to the cell wall reinforcement via apposition of suberin, lignin and callose (Pugin et al. 1997). These are major cell wall components containing lipid polyester and phenolic moieties that impart resistance to pathogens (Pollard et al. 2008; Vanholme et al. 2010). Thus, the accumulation of lipid groups might be related reinforcement of the cell wall physical barrier (Martín et al. 2005). Based on the molecular mechanism model proposed by Coelho et al. (2011), Q. suber will also upregulate phenylpropanoid metabolism upon recognition of P. cinnamomi effector molecules, leading to a cascade of events that culminates in cell wall reinforcement. In addition, suberin has been positively correlated with resistance to Phytophthora invasion (Thomas et al. 2007) and cork oak is notorious for suberin synthesis to protect it against abiotic and biotic stresses (Cordeiro et al. 1998). Inoculation of Pinus pinaster with Fusarium circinatum induced the accumulation of methylesterified pectin polysaccharides and the reduction of non-esterified pectin polysaccharides (Vivas et al. 2014). Similar carbohydrate patterns were observed in the samples analysed in the present work and support the use of methylesterified pectins (band Q10) as biomarkers for the identification of resistant individuals after biotic stress (Taoutaou et al. 2012; Vivas et al. 2014).

Mycelium of P. cinnamomi also showed distinct metabolic patterns when exposed to $Q$. suber root exudates. A total of six distinct patterns were identified, suggesting that mycelium of $P$. cinnamomi rearranged its nutritional metabolism in the presence of water-soluble root exudates. Also one might assume natural adjustments of the metabolic profile during nutrient depletion (Chen and Zentmyer 1970). FT-IR analysis revealed that bands putatively assigned to lipid (P3 and P8), protein (P4 and P5) and cell wall (P11) groups were detected in higher proportions in mycelium exposed to root exudates at 8 and 24 hpe but not at 16 hpe. It is not clear whether the increment in protein content is related to the synthesis of effector proteins. However, synthesis of effector proteins and elevated activities of plant cell wall degrading enzymes such as pectinases have been observed when Phytophthora spp., including P. cinnamomi PA-45, infect host plants, including Q. suber (Horta et al. 2008; Martin and Kamoun 2012). Accumulation of lipid (band P2 and P6) groups in mycelium exposed to root exudates was also observed with time. In addition to effector proteins, which are characterized as narrow host range effectors, there are others, such as glucans and fatty acids, which are synthesized by broad host range pathogens like P. cinnamomi (Tyler 2002). Unfortunately, FT-IR does not have sufficient resolution to identify single molecules. Nevertheless, our data corroborate previous results, which showed the capacity of Phytophthora to detect and respond to root exudates of woody plants, including from Quercus (Kozlowski 1997; Cots and Tuset 2002).

It is well known that the outcome of plant-pathogen interactions is a balance between pathogen invasion machineries and host defence responses (Jones and Dangl 2006). The work reported here has shown that the interaction between cork oak plants and P. cinnamomi is highly complex, with both biological systems accommodating their metabolic profiling within hours of the initiation of the interaction. The two distinct metabolic patterns observed in the host with time after inoculation could also be an adaptation of the pathogen to acquire nutrients during the transition from a biotrophic to a necrotrophic life strategy (Qutob et al. 2002). The shift in the host metabolic pattern of carbohydrate and lipid groups suggests a remarkable and dynamic host response to P. cinnamomi invasion and that $Q$. suber seedlings were resistant to pathogen invasion. On the other hand, alterations in the pathogen metabolic pattern of carbohydrate, lipid and protein groups were remarkable in the presence of cork oak root exudates. Overall, these results demonstrated that the metabolic patterns of both biological systems are quite dynamic with time of interaction and that this effect should be taken into account when discriminating metabolic patterns from biological systems, especially during the early hours of plantpathogen interactions.

\section{Acknowledgements}

Authors are grateful to anonymous reviewers and to the editor for their comments and suggestions. Comments and correspondence from H.M.G.G. Gaspar helped us to clarify arguments. PH has a postdoc fellowship from the Portuguese Foundation to Science and Technology (FCT) (SFRH/BPD/78931/2011). This study is part of research projects supported by the Spanish Ministry of Science and Innovation and co-financed by European Regional Development Fund (ERDF): DECOVA (AGL2009-12243-CO2-01) and by the Portuguese Fundação para Ciência e a Tecnologia (PEst-OE/QUI/UI4023/2011).

\section{References}

Allwood, J. W.; Ellis, D. I.; Heald, J. K.; Goodacre, R.; Mur, L. A. J., 2006: Metabolomic approaches reveal that phosphatidic and phosphatidyl glycerol phospholipids are major discriminatory non-polar metabolites in responses by Brachypodium distachyon to challenge by Magnaporthe grisea. Plant J. 46, 351-368.

Asai, S.; Mase, K.; Yoshioka, H., 2010: A key enzyme for flavin synthesis is required for nitric oxide and reactive oxygen species production in disease resistance. Plant J. 62, 911-924.

Brasier, C. M., 2008: The biosecurity threat to the UK and global environment from international trade in plants. Plant. Pathol. 57, 792808.

Brasier, C. M.; Robredo, F.; Ferraz, J. F. P., 1993: Evidence for Phytophthora cinnamomi involvement in Iberian oak decline. Plant. Pathol. 42, 140-145.

Brereton, R. G., 2009: Chemometrics for Pattern Recognition. Chichester: Wiley-Blackwell, pp. 522.

Bugalho, M. N.; Caldeira, M. C.; Pereira, J. S.; Aronson, J.; Pausas, J. G., 2011: Mediterranean cork oak savannas require human use to sustain biodiversity and ecosystem services. Front. Ecol. Environ. 9, 278-286.

Cameron, D. D.; Coats, A. M.; Seel, W. E., 2006: Differential resistance among host and non-host species underlies the variable success of the hemi-parasitic plant Rhinanthus minor. Ann. Bot. 98, 1289-1299.

Camilo-Alves, C. D. E. P.; da Clara, M. I. E.; Ribeiro, N. M. C. D., 2013: Decline of Mediterranean oak trees and its association with Phytophthora cinnamomi: a review. Eur. J. For. Res. 132, 411-432. 
Chalmers, J. M.; Griffiths, P. R., 2002: Handbook of Vibrational Spectroscopy. Chichester: Wiley-Blackwell, pp. 3862.

Chen, D. W.; Zentmyer, G. A., 1970: Production of sporangia by Phytophthora cinnamomi in axenic culture. Mycologia 62, $397-402$.

Coates, J., 2000: Interpretation of infrared spectra, a practical approach. In: Encyclopedia of Analytical Chemistry. Ed. by Meyers, R. A. Chichester: Wiley-Blackwell, pp. 10815-10837.

Coelho, A. C.; Horta, M.; Ebadzad, G.; Cravador, A., 2011: Quercus suber - Phytophthora cinnamomi interaction: a hypothetical molecular mechanism model. N. Z. J. For. Sci. 41S, S143-S157.

Conrad, A. O.; Rodriguez-Saona, L. E.; McPherson, B. A.; Wood, D. L.; Bonello, P., 2014: Identification of Quercus agrifolia (coast live oak) resistant to the invasive pathogen Phytophthora ramorum in native stands using Fourier-transform infrared (FT-IR) spectroscopy. Front. Plant Sci. 5, 521.

Corcobado, T.; Solla, A.; Madeira, M. A.; Moreno, G., 2013: Combined effects of soil properties and Phytophthora cinnamomi infections on Quercus ilex decline. Plant Soil 373, 403-413.

Corcobado, T.; Cubera, E.; Juárez, E.; Moreno, G.; Solla, A., 2014: Drought events determine performance of Quercus ilex seedlings and increase their susceptibility to Phytophthora cinnamomi. Agric. For. Meteorol. 192-193, 1-8.

Cordeiro, N.; Belgacem, M. N.; Silvestre, A. J. D.; Neto, C. P.; Gandini, A., 1998: Cork suberin as a new source of chemicals. 1. Isolation and chemical characterization of its composition. Int. J. Biol. Macromol. 22, 71-80.

Cots, F.; Tuset, J. J., 2002: Influence of culture water-solution of five species of Mediterranean Quercus in the asexual reproduction of Phytophthora cinnamomi. IOBC-WPRS Bull. 25, 53-56.

De Jong, C. F.; Laxalt, A. M.; Bargmann, B. O. R.; de Wit, P.; Joosten, M.; Munnik, T., 2004: Phosphatidic acid accumulation is an early response in the Cf-4/Avr4 interaction. Plant J. 39, 1-12.

Enkerli, K.; Hahn, M. G.; Mims, C. W., 1997: Immunogold localization of callose and other plant cell wall components in soybean roots infected with the oomycete Phytophthora sojae. Can. J. Bot. 75, 1509-1517.

Fiehn, 0., 2002: Metabolomics - the link between genotypes and phenotypes. Plant Mol. Biol. 48, 155-171.

Gidman, E.; Goodacre, R.; Emmett, B.; Smith, A. R.; Gwynn-Jones, D., 2003: Investigating plant-plant interference by metabolic fingerprinting. Phytochemistry 63, 705-710.

Hall, R. D., 2006: Plant metabolomics: from holistic hope, to hype, to hot topic. New Phytol. 169, 453-468.

Hardham, A. R., 2005: Phytophthora cinnamomi. Mol. Plant Pathol. 6, 589-604.

Horta, M.; Sousa, N.; Coelho, A. C.; Neves, D.; Cravador, A., 2008: In vitro and in vivo quantification of elicitin expression in Phytophthora cinnamomi. Physiol. Mol. Plant Pathol. 73, 48-57.

Horta, M.; Caetano, P.; Medeira, C.; Maia, I.; Cravador, A., 2010: Involvement of the beta-cinnamomin elicitin in infection and colonisation of cork oak roots by Phytophthora cinnamomi. Eur. J. Plant Pathol. 127, 427-436.

Hückelhoven, R., 2007: Cell wall associated mechanisms of disease resistance and susceptibility. Annu. Rev. Phytopathol. 45, 101-127.

Jain, A.; Nandakumar, K.; Ross, A., 2005: Score normalization in multimodal biometric systems. Pattern Recognit. 38, $2270-2285$.

Jones, J. D. G.; Dangl, J. L., 2006: The plant immune system. Nature 444, 323-329.

Kamnev, A. A.; Ristic, M.; Antonyuk, L. P.; Chernyshev, A. V.; Ignatov, V. V., 1997: Fourier transform infrared spectroscopic study of intact cells of the nitrogen-fixing bacterium Azospirillum brasilense. J. Mol. Struct. 408, 201-205.

Kamoun, S.; van West, P.; Vleeshouwers, V.; de Groot, K. E.; Govers, F., 1998: Resistance of Nicotiana benthamiana to Phytophthora infestans is mediated by the recognition of the elicitor protein INF1. Plant Cell 10, 1413-1425.

Kelley, B. S.; Lee, S. J.; Damasceno, C. M. B.; Chakravarthy, S.; Kim, B. D.; Martin, G. B.; Rose, J. K. C., 2010: A secreted effector protein (SNE1) from Phytophthora infestans is a broadly acting suppressor of programmed cell death. Plant J. 62, 357-366.

Kim, J. K.; Bamba, T.; Harada, K.; Fukusaki, E.; Kobayashi, A., 2007: Time-course metabolic profiling in Arabidopsis thaliana cell cultures after salt stress treatment. J. Exp. Bot. 58, 415-424.

Kozlowski, T. T., 1997: Responses of woody plants to flooding and salinity. Tree Physiol. 17, 490-519.

Lanoue, A.; Burlat, V.; Henkes, G. J.; Koch, I.; Schurr, U.; Röse, U. S. R., 2010: De novo biosynthesis of defense root exudates in response to Fusarium attack in barley. New Phytol. 185, 577-588.

Lecellier, A.; Mounier, J.; Gaydou, V.; Castrec, L.; Barbier, G.; Ablain, W.; Manfait, M.; Toubas, D.; Sockalingum, G. D., 2014: Differentiation and identification of filamentous fungi by high-throughput FTIR spectroscopic analysis of mycelia. Int. J. Food Microbiol. 168-169, $32-41$.

Logan, M., 2010: Biostatistical Design and Analysis Using R: A Practical Guide. Chichester: Wiley-Blackwell, pp. 576.

Martin, F.; Kamoun, S., 2012: Effectors in Plant-Microbe Interactions. Malaysia: Wiley-Blackwell, pp. 426.

Martin, J. A.; Solla, A.; Woodward, S.; Gil, L., 2007: Detection of differential changes in lignin composition of elm xylem tissues inoculated with Ophiostoma novo-ulmi using Fourier transform-infrared spectroscopy. For. Pathol. 37, 187-191.

Martin, J. A.; Solla, A.; Coimbra, M. A.; Gil, L., 2008: Metabolic fingerprinting allows discrimination between Ulmus pumila and U. minor, and between U. minor clones of different susceptibility to Dutch elm disease. For. Pathol. 38, 244-256.

Martín, J. A.; Solla, A.; Coimbra, M. A.; Gil, M., 2005: Metabolic distinction of Ulmus minor xylem tissues after inoculation with Ophiostoma novo-ulmi. Phytochemistry 66, 2458-2467.

Medeira, C.; Quartin, V.; Maia, I.; Diniz, I.; Matos, M. C.; Semedo, J. N.; Scotti-Campos, P.; Ramalho, J. C.; Pais, I. P.; Ramos, P.; Melo, E.; Leitao, A. E.; Cravador, A., 2012: Cryptogein and capsicein promote defence responses in Quercus suber against Phytophthora cinnamomi infection. Eur. J. Plant Pathol. 134, 145-159.

Moralejo, E.; Garcia-Munoz, J. A.; Descals, E., 2009: Susceptibility of Iberian trees to Phytophthora ramorum and P. cinnamomi. Plant. Pathol. 58, 271-283.

Moreira, A. C.; Martins, J. M. S., 2005: Influence of site factors on the impact of Phytophthora cinnamomi in cork oak stands in Portugal. For. Pathol. 35, 145-162.

Morris, V. J.; Ring, S. G.; MacDougall, A. J.; Wilson, R. H., 2003: Biophysical characterization of plant cell walls. In: The Plant Cell Wall. Ed. by Rose, J. K. C. Boca Raton, USA: CRC Press, pp. 55-94.

Myers, N.; Mittermeier, R. A.; Mittermeier, C. G.; da Fonseca, G. A. B.; Kent, J., 2000: Biodiversity hotspots for conservation priorities. Nature 403, 853-858.

Oßwald, W.; Fleischmann, F.; Rigling, D.; Coelho, A. C.; Cravador, A.; Diez, J.; Dalio, R. J.; Horta Jung, M.; Pfanz, H.; Robin, C.; Sipos, G.; Solla, A.; Cech, T.; Chambery, A.; Diamandis, S.; Hansen, E.; Jung, T.; Orlikowski, L. B.; Parke, J.; Prospero, S.; Werres, S., 2014: Strategies of attack and defence in woody plant-Phytophthora interactions. For. Pathol. 44, 169-190.

Pinto-Correia, T.; Godinho, S., 2013: Changing agriculture-changing landscape: what is going on in the high nature valued Montado landscapes of southern Portugal. In: Agriculture in Mediterranean Europe: Between Old and New Paradigms. Ed. by Ortiz-Miranda, D.; Moragues-Faus, A.; Arnalte-Alegre, E. Bingley: Emerald Group Publishing, pp. 75-90. 
Pinto-Correia, T.; Menezes, H.; Barroso, L. F., 2014: The landscape as an asset in southern european fragile agricultural systems: contrasts and contradictions in land managers attitudes and practices. Landsc. Res. 39, 205-217.

Pollard, M.; Beisson, F.; Li, Y.; Ohlrogge, J. B., 2008: Building lipid barriers: biosynthesis of cutin and suberin. Trends Plant Sci. 13, 236246.

Pugin, A.; Frachisse, J. M.; Tavernier, E.; Bligny, R.; Gout, E.; Douce, R.; Guern, J., 1997: Early events induced by the elicitor cryptogein in tobacco cells: involvement of a plasma membrane NADPH oxidase and activation of glycolysis and the pentose phosphate pathway. Plant Cell 9, 2077-2091.

Qutob, D.; Kamoun, S.; Gijzen, M., 2002: Expression of a Phytophthora sojae necrosis-inducing protein occurs during transition from biotrophy to necrotrophy. Plant J. 32, 361-373.

R Core Team, 2013. R Foundation for Statistical Computing. Vienna: Austria. http://www.R-project.org/.

Robin, C.; Capron, G.; Desprez-Loustau, M. L., 2001: Root infection by Phytophthora cinnamomi in seedlings of three oak species. Plant. Pathol. 50, 708-716.

Spiteller, G., 2003: The relationship between changes in the cell wall, lipid peroxidation, proliferation, senescence and cell death. Physiol. Plant. 119, 5-18.

Stuart, B. H., 2004: Infrared Spectroscopy: Fundamentals and Applications. Chichester: John Wiley \& Sons, pp. 242.

Taoutaou, A.; Socaciu, C.; Pamfil, D.; Fetea, F.; Balazs, E.; Botez, C., 2012: New markers for potato late blight resistance and susceptibility using FTIR spectroscopy. Not. Bot. Horti. Agrobot. 40, 150-154.

Testerink, C.; Munnik, T., 2005: Phosphatidic acid: a multifunctional stress signaling lipid in plants. Trends Plant Sci. 10, $368-375$.

Thomas, R.; Fang, X.; Ranathunge, K.; Anderson, T. R.; Peterson, C. A.; Bernards, M. A., 2007: Soybean root suberin: anatomical distribution, chemical composition, and relationship to partial resistance to Phytophthora sojae. Plant Physiol. 144, 299-311.

Torres, M. A.; Jones, J. D. G.; Dangl, J. L., 2006: Reactive oxygen species signaling in response to pathogens. Plant Physiol. 141, $373-378$.

Tyler, B. M., 2002: Molecular basis of recognition between Phytophthora pathogens and their hosts. Annu. Rev. Phytopathol. 40, $137-167$.

Underwood, W., 2012: The plant cell wall: a dynamic barrier against pathogen invasion. Front. Plant Sci. 3, 85.

Vanholme, R.; Demedts, B.; Morreel, K.; Ralph, J.; Boerjan, W., 2010: Lignin biosynthesis and structure. Plant Physiol. 153, 895-905.

Vega-Sanchez, M. E.; Redinbaugh, M. G.; Costanzo, S.; Dorrance, A. E., 2005: Spatial and temporal expression analysis of defense-related genes in soybean cultivars with different levels of partial resistance to Phytophthora sojae. Physiol. Mol. Plant Pathol. 66, 175-182.

Vivas, M.; Nunes, C.; Coimbra, M. A.; Solla, A., 2014: Maternal effects and carbohydrate changes of Pinus pinaster after inoculation with Fusarium circinatum. Trees 28, 373-379.

Wang, X.; Devaiah, S. P.; Zhang, W.; Welti, R., 2006: Signaling functions of phosphatidic acid. Prog. Lipid Res. 45, $250-278$.

Wehrens, R., 2011: Chemometrics with R: Multivariate Data Analysis in the Natural Sciences and Life Sciences. Heidelberg, DE: Springer, pp. 285.

\section{Supporting Information}

Additional Supporting Information may be found in the online version of this article:

Figure S1. Heatmap of FT-IR bands from roots of Quercus suber.

Figure S2. Heatmap of FT-IR bands from mycelium of Phytophthora cinnamomi.

Table S1. (a) Correlation table of absorbance values of FT-IR bands from Quercus suber roots challenged with Phytophthora cinnamomi when subtracted from the absorbance values of FT-IR bands of mock-inoculated $Q$. suber roots. (b) Corresponding statistical values ( $q$-values) obtained from the correlation table (Table S1a).

Table S2. (a) Correlation table of the absorbance values of FT-IR bands from Phytophthora cinnamomi when exposed to Quercus suber root exudates after subtracting the absorbance values of FT-IR bands from mock-exposed P. cinnamomi mycelium. (b) Corresponding statistical values ( $q$-values) obtained from the correlation table (Table S2a). 